\title{
Short-term study on the yak dung seed bank on the Qinghai-Tibetan Plateau: effects of grazing season, seed characteristics and forage preferences
}

\author{
Shulin Wang (D) Fujiang Hou
}

Received: 15 March 2021 / Accepted: 12 May 2021 / Published online: 3 June 2021

(C) The Author(s) 2021

\begin{abstract}
Aims Viable seeds in herbivore dung constitute the dung seed bank, and the contribution of livestock dung to this seed bank in grazing pastures is often overlooked. Grazing season (warm and cold), seed characteristics (size and shape), and forage preference are the main factors that affect the size and composition of the dung seed bank and ultimately affect grassland ecology. However, how these three factors interact is unclear.

Methods We collected yak dung as well as seeds of the common plant species from warm- and coldseason alpine meadows in northeastern QinghaiTibetan Plateau, and explored how grazing season (warm and cold), seed characteristics (size and shape) and foraging preferences (temporary cages method) affects yak dung seedling density, richness and diversity in an alpine pasture.

Results Forty-three plant species (mainly perennials) germinated from yak dung. Dung seedling density, richness, and diversity did not differ significantly between the two grazing seasons. Small
\end{abstract}

Responsible Editor: Jeffrey Walck

S. Wang $\cdot$ F. Hou $(\bowtie)$

State Key Laboratory of Grassland Agro-Ecosystems, Key Laboratory of Grassland Livestock Industry Innovation, Ministry of Agriculture and College of Pastoral Agriculture, Science and Technology, Lanzhou University, LanzhouGansu 730000, China

e-mail: cyhoufj@1zu.edu.cn to medium-sized spherical seeds (seed size $<10$ $\mathrm{mg}$, shape index $<0.5$ ) had the greatest germination potential.

Conclusions Yaks vary their forage preference depending on the season (phenological period), and endozoochory occurs throughout both grazing seasons. Seed shape and size directly regulate the dung seedling density, richness, and diversity. Dung seedlings increase the heterogeneity of the aboveground vegetation near the microsites of the dung pieces and therefore promote grassland patching. Our study demonstrates that grazing season, seed characteristics, and yak forage preferences affect the dung seed bank in grazing ecosystems.

Keywords Alpine meadow · Dung seedling · Endozoochory $\cdot$ Forage selection $\cdot$ Grazing ecosystems $\cdot$ Seed germination

\section{Introduction}

Mature plant seeds are sometimes consumed by livestock while foraging, and some of the seeds may survive passage through the digestive tract and are ultimately deposited in dung. These viable seeds in large-herbivore feces constitute the dung seed bank (Iravani et al. 2011; Wang et al. 2019). The passage of seeds through the digestive tract of animals often improves germination success (Wang et al. 2017), and the organic matter and nutrients in livestock dung 
can promote seedling emergence and growth (Woldu and Saleem 2000; Traveset et al. 2001; Nchanji and Plumptre 2003). Myers et al. (2004) reported that more than 70 plant species, including native and alien herbs, shrubs, and trees, were able to germinate from deer dung pellets collected over one year in North America. Notably, more than 30 seeds could germinate from a single dung pellet taken from samples collected in each month of the year.

Livestock manure is an intermediary for pasture seed transmission and soil seed bank composition, bringing about changes in grassland vegetation composition (Elisabeth and Han 2003). Fecal decay, dung-borne seed germination, and establishment of seedlings in soil, i.e., endozoochorous seed dispersal, increase the similarity of plant communities between different types of grazed grasslands and foster diversity among grassland plants within a local community (Malo and Suárez 1995). It is assumed that livestock-mediated endozoochory increases plant species diversity and influences large-scale spatial community composition in grazed ecosystems by promoting intercommunity seed flow (Stroh et al. 2011). Therefore, studies of the composition, size, and ecological characteristics of the dung seed bank have always been at the forefront of research concerning the ecology of grazing pastures (D'Hondt and Hoffmann 2015).

The factors affecting the properties of the dung seed bank primarily include grazing season (warm vs. cold), seed traits (size and shape), and livestock forage preference. The size and components of the dung seed bank vary in different grazing seasons. For example, in the rotation grazing system on the Loess Plateau of northwestern China, the Tan sheep (Ovis aries) dung seed bank density is greater in the cold grazing season than in the warm season because the cold season is the peak period during which seeds mature and sheep have a greater opportunity to ingest them (Wang et al. 2019). Seed traits, such as size and seed shape, also significantly affect their ability to germinate successfully after passing through the digestive tract of animals (Wang et al. 2017). Some studies have shown that medium-sized and spherical seeds have greater germination potential after passage through the sheep gut, as seeds in this category have a short retention time in the digestive tract of livestock, which reduces the destructive effects of ruminant digestion (Manzano et al. 2005; Wang et al. 2018).
To meet ever-changing nutritional needs and adapt to a changing environment, grazing livestock may alter their feeding strategies, i.e., forage preferences, based on forage palatability and whether they are provided supplemental feed (Newman et al. 1995). For example, sheep were found to select certain plant species (e.g., graminoids) as forage under a low stocking rate in abandoned dry grasslands of the southwestern Italian Alps (Pittarello et al. 2017). Also, lambs preferred Plantains more in the spring than in summer (Pain et al. 2014). Because only those seeds ingested by animals will be excreted with feces to form the dung seed bank, foraging preferences have an impact on the composition and structure of the bank (Wang et al. 2017; Wang et al. 2019).

The Qinghai-Tibetan Plateau (QTP) extends $~ 2.5$ million $\mathrm{km}^{2}$, making it the largest grazing ecosystem in Eurasia (Cai et al. 2014). The most common management method for grazing in the QTP grasslands is nomadic, where transhumant flocks move seasonally with their herders between fixed warm and cold pastures (Wang et al. 2012; Zhouguadongzhu 2019). More than 13.3 million yaks (Bos grunniens, the dominant livestock) graze the QTP (Yu et al. 2013b), which is important for nomadic populations in southwest China in terms of both herder survival and grassland livestock production. Annually, 40 million tons of dung are directly deposited onto the QTP grassland (Liu et al. 2018). Research on the ecological significance of livestock dung on the QTP has been neglected (Yang et al. 2019), especially the ecological impact of the dung seed bank in grasslands. Moreover, the effects of grazing season, seed traits, and forage preferences on the size and structure of the yak dung seed bank in alpine meadows of the QTP have not been intensively studied (Yu et al. 2013a), and neither have the interactions between these three factors.

In this study, we collected yak dung as well as seeds of the common plant species from warm- and cold-season pastures in northeastern QTP, and the forage preferences of yaks were also investigated. The objectives of this research were to study: (i) the size and species composition of the dung seed bank in the warm and cold grazing seasons and the relationship between the dung seed bank and aboveground vegetation; (ii) the relationship between seed traits of the aboveground plant species and the density, richness, and diversity of dung seedling; 
and, (iii) the effects of interactions between grazing seasons, seed traits, and forage preference on the size and composition of the dung seed bank. We hypothesized that grazing season could affect the yak dung seed bank either directly or indirectly, i.e., as a consequence of changes in yak forage preferences or the composition of the aboveground vegetation and seed characteristics. The results enhance our understanding of the ecological significance of the dung seed bank for grassland development and the mechanisms of grass-animal interactions in grazing ecosystems.

\section{Materials and methods}

Study sites

The study was undertaken at the Lanzhou University Research Station in Maqu County, Gansu Province, China $\left(101^{\circ} 53^{\prime} \mathrm{E}, 33^{\circ} 58^{\prime} \mathrm{N}, 3520 \mathrm{~m}\right.$ a.s.l.). This area is located in northeastern QTP. The climate is cold and humid, with only a warm season (May to October) and cold season (November to April) (Sun et al. 2015). There is no absolute frostfree period throughout the year. The annual average temperature during $2010-2019$ was $\sim 1.2^{\circ} \mathrm{C}$, and the highest temperatures occur from June to August, with an average of $\sim 12^{\circ} \mathrm{C}$, and the lowest temperatures (average $-10^{\circ} \mathrm{C}$ ) occur from December to February. The average annual rainfall is $\sim 620 \mathrm{~mm}$, which occurs mainly during the forage growing season (May to September). The soils are classified as Mat-Cryic Cambisols based on previous experimental work (Sun et al. 2015), and the vegetation is characteristic of a typical alpine meadow (Yang et al. 2019). Cyperaceae (Kobresia graminifolia, Kobresia humilis, and Kobresia pygmaea) constitute the foundational species, and Poaceae (Elymus nutans and Poa pratensis), Compositae (Saussurea hieracioides, Aster diplostephioides, and Anaphalis lactea), Ranunculaceae (Anemone rivularis, Anemone trullifolia, and Anemone obtusiloba), and other associated plants are widely distributed among them, in addition to scattered Potentilla fruticosa shrubs (Yang et al. 2019). The entire study area has undulating mountains, with steep, variable, complex, and fragmented terrain. The total grassland area of the Maqu Research Station is $\sim 5000$ ha, the usable pasture area is $\sim 4500$ ha, the annual average fresh forage yield is $\sim 5925 \mathrm{~kg} / \mathrm{ha}$, and yaks are the only grazing livestock.

\section{Rotational grazing of yaks}

Pastures at Maqu Research Station are rotationally grazed by yaks, the traditional livestock breed on the QTP, since 2012. Two flatland areas (vegetation structure and composition are similar) near the station, 2 $\mathrm{km}$ apart, were randomly selected as the warm-season pasture (36 ha, Fig. 1A) and cold-season pasture (36 ha, Fig. 1B). Each pasture was divided into six paddocks (6 ha each; 12 grazing paddocks in total) using wire mesh to give six replicates. In each year since 2012, warm-season grazing was from June 1 to October 4 (126 days duration) with three 42-day (6 paddocks $\times 7$ days) rotational rounds; for each round, twenty 1 -year-old yaks grazed for 7 days in one paddock and then rotated to the next paddock for 7 days of grazing. Each warm-season paddock was grazed at moderate intensity (3.33 yak ha ${ }^{-1}$ ) according to a previous study (Yang et al. 2019). Cold-season grazing was from November 1 to January 23 (84 days duration) with two 42-day rotational rounds; for each round, yaks grazed for 7 days in one paddock and then rotated to the next paddock for 7 days of grazing. Each cold-season paddock was also grazed at moderate intensity $\left(3.33 \mathrm{yak} \mathrm{ha}^{-1}\right)$. Yaks were allowed to graze freely outside the two pastures during the other period (October 5 to October 31; January 24 to May 31). Yaks were not given any supplemental feed during the grazing experimental period. During the warm season, yaks entered the pasture at 06:00 and returned to the night pen at 19:00; in the cold season, these respective times were 07:00 and 18:00.

Since the grazing season treatment is not spatially replicated, 'grazing season' could be considered to be pseudo-replicated (Hurlbert 1984).

Forage preferences of yaks

Yaks generally feed on the vegetative organs (e.g., foliage and stems) of forages, but the aboveground vegetation of alpine meadows is mainly composed of herbaceous plants, and the reproductive organs (e.g., 


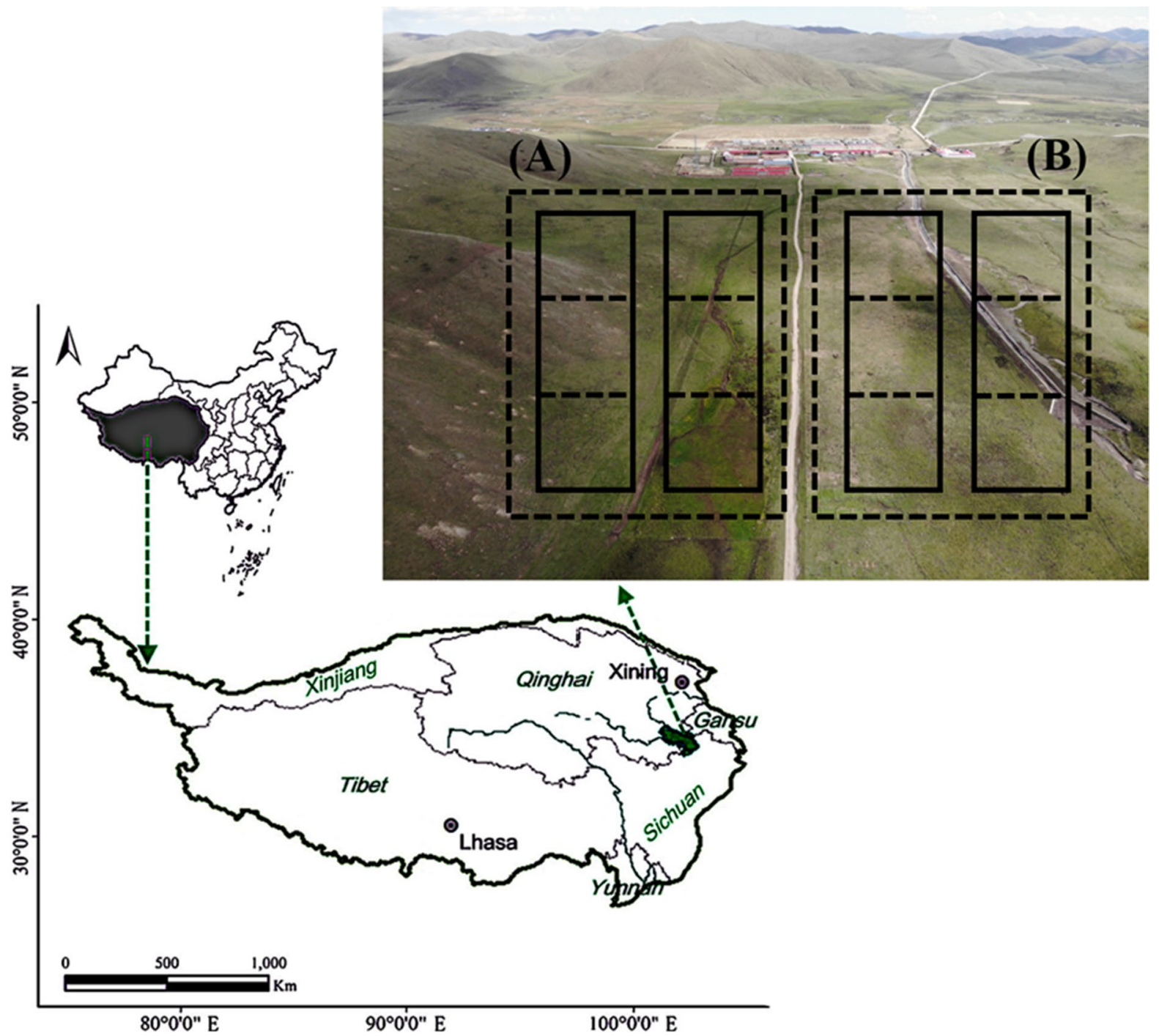

Fig. 1 Location of the Maqu Research Station on the Qinghai-Tibetan Plateau in China. (A) Warm-season pasture. (B) Cold-season pasture. Each pasture was divided into six paddocks (6 ha each) for yak rotational grazing

flowers, fruits and achene) and vegetative organs are closely connected and difficult to separate. Yaks feed on the vegetative organs and at the same time intake the reproductive organs (Janzen 1984). Therefore, we measured yak forage preferences by weighing the mass of each individual plant species that had been ingested.

During mid-August (warm season) 2019, in each warm-season paddock, a $1 \mathrm{~m} \times 1 \mathrm{~m} \times 1 \mathrm{~m}$ iron cage (Fig. 2) was randomly placed in each paddock to estimate the forage preferences of yaks (McNaughton et al. 1996). Two quadrats $(0.5 \mathrm{~m} \times 0.5 \mathrm{~m}$ each, one inside the cage and the other outside the cage) were established, and 6 paired quadrats ( 6 outside cage +6 inside cage) in total were established within all 6 paddocks. For each quadrat (both inside and outside the cage), we cut each individual species, loaded each sample into a paper envelope, and dried it to a constant weight at $65^{\circ} \mathrm{C}$

We using Ivlev's index following Jacobs (1974) to calculated the forage preferences of yaks:

Ivlev' sindex $=\frac{r-p}{r+p-2 r p}$ 


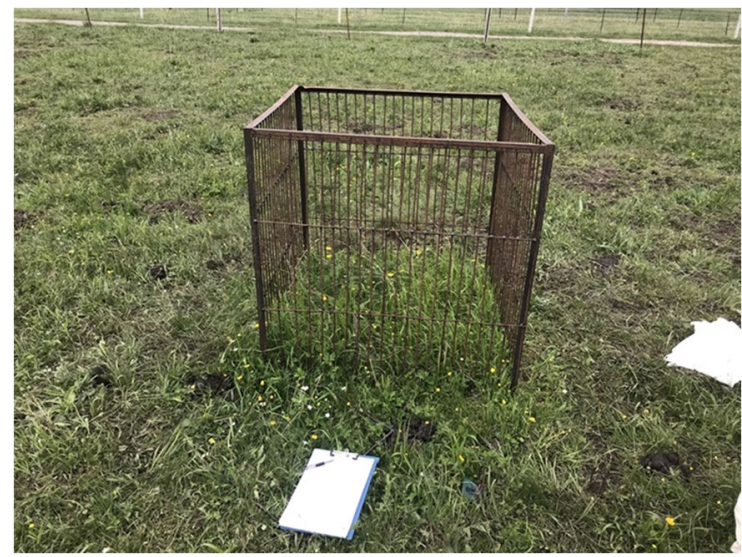

Fig. 2 Iron cages $(1 \mathrm{~m} \times 1 \mathrm{~m} \times 1 \mathrm{~m})$ were used to investigate the forage preferences of yaks

where $r$ is the proportion (based on mass) of an individual plant species in the overall intake forage (outside the cage), and $p$ is the proportional availability (based on mass) of the species in the environment (inside the cage) (Jacobs 1974). Ivlev's index scores range between -1 and +1 . A positive score for a particular plant species indicates that herbivores consume it preferentially, whereas a negative score indicates their tendency to avoid it (Jacobs 1974; Bagchi and Ritchie 2010).

As the study-site region began experiencing colder temperatures in early November (cold-season grazing period), the temperature dropped sharply accompanied by substantial snowfall, resulting in withering of the forage (standing litters) (Sun et al. 2018); therefore, Ivlev's index could not be calculated during this period. The nutrient content of the grass also decreased to a minimum at this time, and all aboveground vegetation was eaten by the yaks, which greatly weakened the forage preference.

\section{Dung collection}

According to our field observations, July is the peak period of plant flowering, while August to September represents the peak period of seed maturation. Importantly, many plant seeds persist and are retained on the plant canopy for several months (Ripa et al. 2020). Therefore, even if the plants had stopped growing during the cold season (November to April), some of the retained seeds still had the potential to be ingested by yaks.
Samples of yak dung were collected from each paddock during both the warm and cold seasons in 2019. Dung pieces were collected from early-August to mid-October for the warm season and from midNovember to mid-January for the cold season. On average, 10 dung pieces were collected per paddock, resulting in a total of 120 (10 pieces $\times 6$ replicates $\times 2$ grazing seasons). The sites where dung was collected were marked by pegs. To avoid seeds that were deposited through wind or other agents onto/in the dung, only fresh dung (i.e., newly defecated, cylindrical, length $\sim 19 \mathrm{~cm}$, diameter $\sim 4 \mathrm{~cm}$ ) was collected. To prevent aboveground seeds from sticking to the dung, we carefully removed the soil and/or litter from the underside of each dung piece (Yu et al. 2013a). Each dung sample was placed in an individual canvas bag (clearly marked) and transported to the laboratory. Each dung sample was dried at $35^{\circ} \mathrm{C}$ for $\sim 72 \mathrm{~h}$ in a drying oven to prevent both decay and the premature germination of seeds in the dung. Importantly, drying at this temperature does not substantively affect the germination potential of seeds in dung samples (Wang et al. 2019). All dried dung samples were weighed and then stored in the dark at room temperature.

\section{Aboveground vegetation}

The aboveground vegetation was surveyed in midAugust, 2019. The species richness (number of plant species; 55 species in both warm- and cold- season pasture) and biomass of aboveground vegetation ( 600 $\mathrm{g} \mathrm{m}^{-2}$ ) peaked during this period, which reflects the productivity of the warm- and/or cold-season pastures. Two quadrats $(0.5 \mathrm{~m} \times 0.5 \mathrm{~m}$ each $)$ were established, paired to the microsites of the collected dung pieces. Therefore, each pasture contributed 12 quadrats (2 quadrats $\times 6$ paddocks, $\mathrm{n}=12$ ). Individual species number (richness) and species density were recorded for each quadrat in each paddock.

Seed size and shape index

From mid-August to mid-November 2019, we manually collected fully mature seeds from the common aboveground vegetation at each of the two pastures, and at least 20 individual plants were sampled for 
each species to eliminate species individual differences (Yu et al. 2012). All species were native and therefore represented both the current and historical species of the local grassland (Wang et al. 2020).

Seeds collected from the same plant species in the two pastures were mixed together. Seeds without appendages were weighed (100 seeds per species; accuracy was $\pm 0.01 \mathrm{mg}$ ). Thirty seeds per species were randomly selected for measurement of length, width, and height using an electronic Vernier caliper under a stereomicroscope (Nikon SMZ 1500, Shanghai, China, $25 \mu \mathrm{m}$ precision). There were six replicates per measurement of each seed size and seed shape index. The shape index (I), i.e., divergence from sphericity, was calculated according to Wang et al. (2019) as the variance of the three main dimensions:

$I=\frac{\left[3\left(X_{L}^{2}+X_{W}^{2}+X_{H}^{2}\right)-\left(X_{L}+X_{W}+X_{H}\right)^{2}\right]}{3^{2}}$

where $X_{L}, X_{W}$ and $X_{H}$ are seed length, width and height, respectively. The $I$ value may range from 0 to 1 , with $I=0$ representing a perfect sphere and $I$ $=1$ representing completely flat or elongated seeds.

\section{Germination}

After weighing each dung piece, the dung piece was compressed gently to avoid damaging seeds, mixed with $\sim 50 \mathrm{~g}$ sterile sand, and spread in a pot (length $35 \mathrm{~cm}$, width $18 \mathrm{~cm}$, height $10 \mathrm{~cm}$ ) at $2 \mathrm{~cm}$ thickness on a 5-cm-thick bed of vermiculite. Pots (each dung piece in one pot) were placed in the Maqu Research Station yard under natural conditions (He et al. 2020). As a control, 10 pots that contained only sterilized sand and vermiculite were placed alongside the dung pots to check for contamination by seeds blown in by wind or other potential means. Pots were watered twice a day (except on rainy days) from January until June, 2020. The experiment was stopped after 6 months because no substantive additional germination had been detected for 2 weeks (Malo 2000). Emerging seedlings were recorded and removed as soon as identified or were transplanted into separate pots for later identification. Whenever seedlings were removed, the dung/ sand mix was stirred to facilitate germination of the remaining buried seeds.
Dung seedling and aboveground vegetation density, richness and diversity indices

Dung seedling density (number of seedlings germinated per unit of dung weight, i.e., seedlings $\mathrm{g}^{-1} \mathrm{dung}$ ) and dung seedling richness (number of seedling species, i.e., species $\mathrm{g}^{-1}$ dung) were determined based on data collected from 60 replicates of each dung sample in each pot. For each seedling pot as well as for the aboveground vegetation quadrat, a Shannon-Wiener diversity index $\left(H^{\prime}\right)$ was calculated as:

$H^{\prime}=-\sum_{i=1}^{s} P_{i} \ln P_{i}$

where $p_{i}$ is the relative proportion of seedling density of the total community (in this study, community refers to the dung seedling bank or aboveground vegetation quadrat), and $s$ is the total number of dung seedlings per each dung sample (i.e., the richness of either dung seedlings or the aboveground vegetation).

\section{Data analysis}

Data analyses were conducted with IBM SPSS (ver. 26.0). We used the least significant difference method to compare differences in data for dung weight, dung seedling density, species richness, and species diversity between the warm and cold grazing seasons. The level of significance used was $P<0.05$. A ShapiroWilk test was used to test the normality of data before comparing mean values. Dung seedling density, species richness, and species diversity in relation to single-seed size or seed shape index were determined by regression analyses. Differences in the composition of each of the dung seedling bank (seedling density) and aboveground vegetation (species density) between the two pastures were compared with a nonmetric multidimensional scaling analysis (using PCORD 5.0) with the Raup-Crick dissimilarity matrix based on the relative density of species in each dung sample or the two grazing-season pastures. The error bars and numbers following averages mean standard error (s.e.).

Structural equation modeling (SEM) was performed using AMOS 24.0 (Arbuckle 2010) and was used to estimate the effect of grazing season on changes in the aboveground vegetation and dung seedling bank (based on seedling density). The core theory of SEM analysis is the covariance of variables and the pseudo-repetition (some treatment lack of 
replication, e.g., grazing season) could also use this analytical method (Wang et al. 2019). We set grazing season and seed trait (i.e., seed size and seed shape index) as fixed effects, while forage preferences (i.e., Ivlev's index), aboveground vegetation, and dung seedling information (i.e., density, richness and diversity) were the response variables. The Chi-squared test was used to evaluate the fit of the model, and the model was deemed to have a good fit when $0 \leq \chi^{2} / \mathrm{df}$ $\leq 2$ and $0.05<P \leq 1$. A $P$ value of $>0.05$ indicated that the covariance structure of the data did not differ significantly from the expected model (Grace 2006).

\section{Results}

Dung weight and seedling composition in different grazing seasons

We weighed 60 dung samples taken from warm- or cold-season paddocks (Fig. 3). The weight of the dried dung pieces during the warm season (167.13 $\pm 38.92 \mathrm{~g}$ ) was significantly less than that during the cold season $(252.93 \pm 59.71 \mathrm{~g})\left(\mathrm{n}=60, \mathrm{~F}_{1,118}=\right.$ 104.41, $P=0.00$ ).

The germination test with yak dung samples taken from the warm- and cold-season grazing paddocks identified a total of 43 plant species representing 19 families (Table 1). Twenty-four common plant

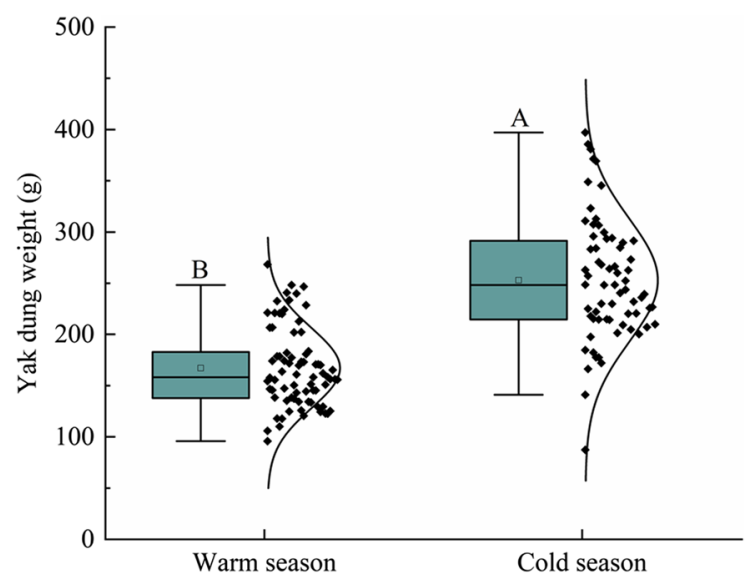

Fig. 3 Dung dry weight differed significantly between the warm and cold seasons. The horizontal line in each box indicates the mean value, and the dot indicates the median. Different letters denote a significant difference between grazing seasons $(\mathrm{n}=60, P<0.05)$ species germinated from both the warm- and coldseason dung samples. For the warm-season dung pieces, 32 species ( 23 perennial +8 annual +1 subshrub) germinated, and the seedling density (17.15 \pm $0.85 \mathrm{~g}^{-1}$ dung) ranged from $0.016 \pm 0.00 \mathrm{~g}^{-1}$ dung ( $A$. diplostephioides, P. kansuensis, E. densa, C. glaucum, E. esula, E. palustre) to $3.13 \pm 0.065 \mathrm{~g}^{-1}$ dung $(P$. aпnиa). For the cold-season dung pieces, 35 species (29 perennial +4 annual +1 sub-shrub +1 fern) germinated successfully, and the dung seedling density $\left(15.16 \pm 0.93 \mathrm{~g}^{-1}\right.$ dung) ranged from $0.016 \mathrm{~g}^{-1}$ dung (O. kansuensis, T. lanceolata, A. lactea, E. regelii, $P$. macrophyllum, $P$. viviparum, $C$. palustris, E. palustre, E. arvense) to $2.49 \mathrm{~g}^{-1}$ dung (A. clavata). There were no significant differences between the warm- and cold-season samples with respect to the average dung seedling density $\left(\mathrm{F}_{1,118}=2.729, P=0.101\right)$, species richness $\left(\mathrm{F}_{1,118}=0.430, P=0.513\right)$, or species diversity $\left(\mathrm{F}_{1,118}=0.079, P=0.78\right)$ (Fig. $\left.4 \mathrm{a}\right)$, implying that the yak-dung samples contained germinable seeds throughout both grazing seasons. With respect to the aboveground vegetation, the values for average species density $\left(\mathrm{F}_{1,22}=4.468, P=0.046\right)$, species richness $\left(\mathrm{F}_{1,22}=5.799, P=0.025\right)$, and species diversity $\left(\mathrm{F}_{1,22}=6.342, P=0.048\right)$ for the cold-season pastures were all significantly greater than the values for the warm-season pastures (Fig. 4b).

Dung seedling density in relation to seed size and seed shape index

Of the 43 plant seed species identified in yak dung samples, mean seed size was $1.47 \mathrm{mg}$, with a range of $0.0024 \mathrm{mg}$ (H. monorchis) to $22.24 \mathrm{mg}$ (T. lanceolata) (Table 2). Thirty-three species (77\%) had a seed size of $<10 \mathrm{mg}$ (small or medium-sized seeds). The mean seed shape index was 0.24 , ranging from 0.0010 (T. lanceolata) to 0.79 (S. purpurea), with 28 species $(65 \%)$ having a shape index of $<0.50$ (spherical seeds).

Seed size had a significant impact on germination success after passage through the livestock digestive tract, as seeds of $<10 \mathrm{mg}$ germinated most successfully (Fig. 5A; Table 3). This result indicated that small or medium-sized seeds had the highest germination potential. Also, as seed shape index increased, dung seedling density decreased (Fig. 5B; Table 3), 
Table 1 Germination density (seedlings $\mathrm{g}^{-1}$ dung, mean \pm s.e., $\mathrm{n}=60$ ) of plant-seed species from yak dung in the two grazing seasons

\begin{tabular}{|c|c|c|c|c|}
\hline Family & Dung seedling species & Functional group & Warm season & Cold season \\
\hline \multirow[t]{5}{*}{ Poaceae } & Agrostis clavata Trin. & $\mathrm{P}$ & $2.34 \pm 0.036$ & $2.49 \pm 0.057$ \\
\hline & Elymus nutans Griseb. & $\mathrm{P}$ & $0.47 \pm 0.014$ & $0.52 \pm 0.025$ \\
\hline & Poa апnиа L.* & A & $3.13 \pm 0.065$ & $0.93 \pm 0.019$ \\
\hline & Poa albertii subsp. poophagorum (Bor) Olonova \& G. Zhu & $\mathrm{P}$ & $0.84 \pm 0.051$ & $0.77 \pm 0.026$ \\
\hline & Stipa purpurea Griseb. & $\mathrm{P}$ & $0.23 \pm 0.014$ & $0.61 \pm 0.012$ \\
\hline \multirow[t]{4}{*}{ Leguminosae } & Blysmus sinocompressus Tang et Wang & $\mathrm{P}$ & & $0.082 \pm 0.00$ \\
\hline & Kobresia pygmaea (C. B. Clarke) C. B. Clarke & $\mathrm{P}$ & & $0.016 \pm 0.00$ \\
\hline & Astragalus polycladus Bur. et Franch. & $\mathrm{P}$ & & $0.13 \pm 0.0057$ \\
\hline & Oxytropis kansuensis Bunge & $\mathrm{P}$ & & $0.016 \pm 0.00$ \\
\hline \multirow[t]{2}{*}{ Cyperaceae } & Tibetia himalaica (Baker) Tsui & $\mathrm{P}$ & $1.76 \pm 0.038$ & $1.90 \pm 0.048$ \\
\hline & Thermopsis lanceolata $\mathrm{R} . \mathrm{Br}$. & $\mathrm{P}$ & $0.94 \pm 0.019$ & $0.72 \pm 0.033$ \\
\hline \multirow[t]{5}{*}{ Asteraceae } & Anaphalis lactea Maxim.* & $\mathrm{P}$ & $0.094 \pm 0.0063$ & $0.016 \pm 0.00$ \\
\hline & Artemisia moorcroftiana Wall. ex DC.* & Sub-shrub & $0.094 \pm 0.0063$ & $0.26 \pm 0.0080$ \\
\hline & Aster diplostephioides (DC.) C. B. Clarke & $\mathrm{P}$ & $0.016 \pm 0.00$ & \\
\hline & Leontopodium nanum (Hook. f. et Thoms.) Hand.-Mazz. & $\mathrm{P}$ & & $0.033 \pm 0.00$ \\
\hline & Ligularia virgaurea (Maxim.) Mattf. & $\mathrm{P}$ & $0.031 \pm 0.00$ & \\
\hline \multirow[t]{5}{*}{ Scrophulariaceae } & Euphrasia regelii Wettst. & $\mathrm{P}$ & & $0.016 \pm 0.00$ \\
\hline & Lancea tibetica Hook. f. et Thoms. & $\mathrm{P}$ & & $0.098 \pm 0.013$ \\
\hline & Pedicularis kansuensis f. albiflora & A & $0.016 \pm 0.00$ & \\
\hline & Veronica biloba L. Mant.* & A & $0.125 \pm 0.0074$ & $0.25 \pm 0.013$ \\
\hline & Veronica eriogyne $\mathrm{H}$. Winkl. & $\mathrm{P}$ & $0.25 \pm 0.0055$ & \\
\hline \multirow[t]{4}{*}{ Polygonaceae } & Polygonum macrophyllum D. Don & $\mathrm{P}$ & $0.031 \pm 0.00$ & $0.016 \pm 0.00$ \\
\hline & Polygonum sibiricum Laxm.* & $\mathrm{P}$ & $0.14 \pm 0.0071$ & $0.049 \pm 0.0082$ \\
\hline & Polygonum viviparum $\mathrm{L}$. & $\mathrm{P}$ & & $0.016 \pm 0.00$ \\
\hline & Rumex patientia $\mathrm{L}$. & $\mathrm{P}$ & & $0.082 \pm 0.0070$ \\
\hline \multirow[t]{2}{*}{ Caryophyllaceae } & Cerastium fontanum subsp. vulgare (Hartman) Greuter \& Burdet* & $\mathrm{P}$ & $1.67 \pm 0.030$ & $0.79 \pm 0.018$ \\
\hline & Stellaria uda Williams* & $\mathrm{P}$ & $0.44 \pm 0.016$ & $0.25 \pm 0.0098$ \\
\hline \multirow[t]{2}{*}{ Rosaceae } & Potentilla anserina $\mathrm{L}$. & $\mathrm{P}$ & $0.47 \pm 0.042$ & $0.082 \pm 0.025$ \\
\hline & Potentilla fragarioides L.* & $\mathrm{P}$ & $0.078 \pm 0.0067$ & $0.23 \pm 0.0073$ \\
\hline \multirow[t]{3}{*}{ Ranunculaceae } & Anemone rivularis var. flore-minore Maxim.* & $\mathrm{P}$ & $0.14 \pm 0.00$ & $0.52 \pm 0.026$ \\
\hline & Caltha palustris $\mathrm{L}$. & $\mathrm{P}$ & & $0.016 \pm 0.00$ \\
\hline & Halerpestes tricuspis (Maxim.) Hand.-Mazz.* & $\mathrm{P}$ & $1.28 \pm 0.029$ & $2.09 \pm 0.022$ \\
\hline \multirow[t]{2}{*}{ Brassicaceae } & Capsella bursa-pastoris (L.) Medic. & A & $0.23 \pm 0.044$ & \\
\hline & Draba nemorosa $\mathrm{L}$. & A & $0.14 \pm 0.013$ & \\
\hline Apiaceae & Pleurospermum uralense Hoffmann & $\mathrm{P}$ & $0.031 \pm 0.00$ & $0.049 \pm 0.00$ \\
\hline Lamiaceae & Elsholtzia densa Benth. & $\mathrm{P}$ & $0.016 \pm 0.00$ & $0.033 \pm 0.00$ \\
\hline Chenopodiaceae & Chenopodium glaucum $\mathrm{L}$. & A & $0.016 \pm 0.00$ & \\
\hline Orchidaceae & Herminium monorchis (L.) R. Br.* & $\mathrm{P}$ & $0.031 \pm 0.00$ & $0.11 \pm 0.0080$ \\
\hline Plantaginaceae & Plantago depressa Willd. & A & $1.06 \pm 0.014$ & $1.31 \pm 0.023$ \\
\hline Euphorbiaceae & Euphorbia esula L. & $\mathrm{P}$ & $0.016 \pm 0.00$ & \\
\hline Onagraceae & Epilobium palustre $\mathrm{L}$. & $\mathrm{P}$ & $0.016 \pm 0.00$ & $0.016 \pm 0.00$ \\
\hline Equisetaceae & Equisetum arvense $\mathrm{L}$. & Pteridophyta & & $0.016 \pm 0.00$ \\
\hline Juncaceae & Juncus bufonius Linn.* & A & $1.09 \pm 0.042$ & $0.59 \pm 0.026$ \\
\hline
\end{tabular}

Perennial (P) and annual (A) grasses and herbs are indicated. *Indicates a significantly difference in germination density between the warm- and cold-season pastures (same row) $(P<0.05)$. Latin names for dung seedling species were taken from the website for Flora Reipublicae popularis Sinicae (http://www.iplant.cn/frps) 


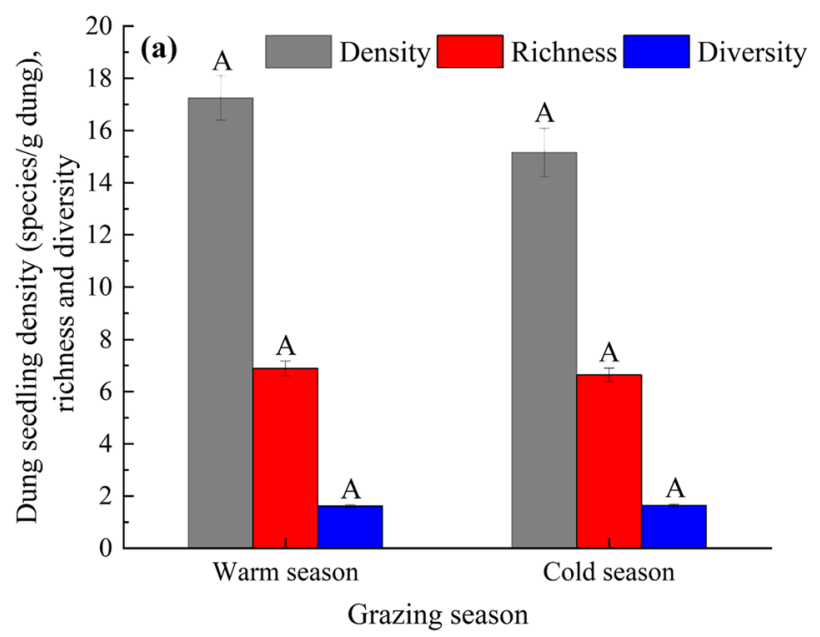

Fig. 4 Density, richness, and diversity of both dung seedlings (a) and the aboveground vegetation (b) during the warm and cold grazing seasons. There were no significant differences between any of the respective warm- and cold-season dung

indicating that spherical seeds (index $<0.50$ ) were more conducive to endozoochorous dispersal.

Yak forage preferences among species of the aboveground vegetation as determined by analysis of plant seed species in yak dung

As shown in Fig. 6, of the 43 plant species identified in yak dung, 17 species (39\%) had a positive Ivlev's index, implying that the yaks preferentially browsed these plants. A total of 19 species (44\%) had an Ivlev's index of 0 , implying that yaks had a moderate preference for these species. Finally, 7 species (16\%) had a negative Ivlev's index, indicating that the yaks tended to avoid these grasses.

Similarity between dung seedlings and aboveground vegetation

An ordination diagram revealed a significant difference in species composition between the dung seedlings and aboveground vegetation in each paddock (Fig. 7). Dung seedlings and the aboveground vegetation clustered together in both the warm and cold grazing seasons. This implied that the dung seedling bank contributed to the diversity of the aboveground vegetation near the microsites of the dung pieces.

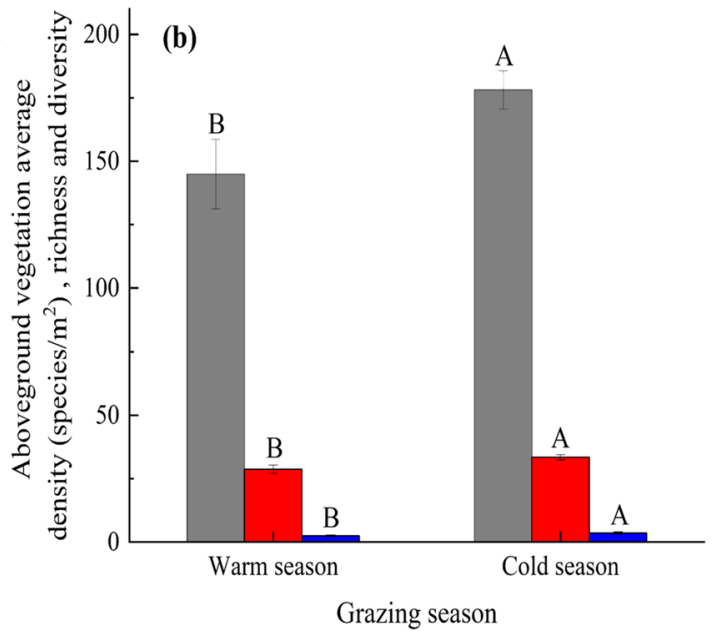

seedling samples $(\mathrm{n}=60, P>0.05)$, although the differences were significant between the two seasons for the aboveground vegetation communities, as indicated by different uppercase letters $(\mathrm{n}=12, P<0.05)$

Effects of grazing season, forage preferences, and seed characteristics on the dung seed bank

Grazing season had no significant direct effect on dung seedling density, seedling richness, or seedling diversity (standardized path coefficients of $0.23 ; P>0.05$; Fig. 8). However, grazing season did have a significant indirect effect, i.e., through the aboveground vegetation, on dung seedling density, richness and diversity $(0.41$, 0.39 and 0.37 , respectively; $P<0.05$ ). Grazing season also had a significant indirect effect, i.e., through selective feeding, on dung seedling density $(0.82, P<0.001)$, richness $(0.66, P<0.01)$, and diversity $(0.64, P<0.01)$.

Both seed size and seed shape index had independent significant direct effects on dung seedling density (0.86 and $0.82, P<0.001)$, richness $(0.78$ and 0.73 , $P<0.001)$, and diversity $(0.69$ and $0.62, P<0.01)$ (Fig. 8).

\section{Discussion}

The size and composition of yak dung seedlings on the QTP

Owing to the various phenological phases of plants, the number of mature seeds and their specific components that are retained on reproductive culms differs 
Table 2 Plant species that germinated from yak dung: seed mass $(\mathrm{mg}$, mean \pm s.e., $\mathrm{n}=6)$ and shape index (mean \pm s.e., $\mathrm{n}=6)$

\begin{tabular}{|c|c|c|}
\hline Dung seedling species & Seed mass (mg) & Shape index \\
\hline A. clavata & $0.085 \pm 0.017$ & $0.79 \pm 0.031$ \\
\hline E. nutans & $3.56 \pm 0.37$ & $0.78 \pm 0.012$ \\
\hline P. аппиа & $0.53 \pm 0.023$ & $0.52 \pm 0.032$ \\
\hline P. albertii & $0.70 \pm 0.14$ & $0.070 \pm 0.060$ \\
\hline S. purpurea & $4.95 \pm 0.031$ & $0.79 \pm 0.022$ \\
\hline A. polycladus & $14.29 \pm 0.053$ & $0.52 \pm 0.0080$ \\
\hline O. kansuensis & $22.24 \pm 0.065$ & $0.13 \pm 0.0067$ \\
\hline T. himalaica & $22.68 \pm 0.031$ & $0.076 \pm 0.031$ \\
\hline T. lanceolata & $22.98 \pm 1.12$ & $0.0010 \pm 0.00$ \\
\hline B. sinocompressus & $0.74 \pm 0.021$ & $0.52 \pm 0.043$ \\
\hline K. pygmaea & $1.03 \pm 0.023$ & $0.53 \pm 0.024$ \\
\hline A. lactea & $0.082 \pm 0.0035$ & $0.73 \pm 0.0097$ \\
\hline A. moorcroftiana & $0.15 \pm 0.043$ & $0.54 \pm 0.0067$ \\
\hline A. diplostephioides & $0.94 \pm 0.021$ & $0.72 \pm 0.42$ \\
\hline L. nanum & $0.091 \pm 0.012$ & $0.52 \pm 0.0067$ \\
\hline L. virgaurea & $1.21 \pm 0.012$ & $0.76 \pm 0.045$ \\
\hline E. regelii & $0.12 \pm 0.016$ & $0.17 \pm 0.0048$ \\
\hline L. tibetica & $0.083 \pm 0.013$ & $0.055 \pm 0.0061$ \\
\hline P. kansuensis & $0.47 \pm 0.041$ & $0.17 \pm 0.0087$ \\
\hline V. biloba & $1.07 \pm 0.054$ & $0.28 \pm 0.015$ \\
\hline V. eriogyne & $0.052 \pm 0.014$ & $0.10 \pm 0.0014$ \\
\hline P. macrophyllum & $1.18 \pm 0.51$ & $0.18 \pm 0.015$ \\
\hline P. sibiricum & $0.65 \pm 0.022$ & $0.078 \pm 0.0049$ \\
\hline$P$. viviparum & $2.95 \pm 0.053$ & $0.24 \pm 0.011$ \\
\hline R. patientia & $1.01 \pm 0.012$ & $0.11 \pm 0.0080$ \\
\hline C. fontanum & $0.17 \pm 0.0048$ & $0.011 \pm 0.00010$ \\
\hline S. $u d a$ & $0.095 \pm 0.0037$ & $0.019 \pm 0.0019$ \\
\hline P. anserina & $0.27 \pm 0.095$ & $0.082 \pm 0.022$ \\
\hline P. fragarioides & $13.27 \pm 0.0021$ & $0.088 \pm 0.0029$ \\
\hline A. rivularis & $6.71 \pm 0.32$ & $0.72 \pm 0.18$ \\
\hline C. palustris & $13.34 \pm 0.053$ & $0.54 \pm 0.0064$ \\
\hline H. tricuspis & $0.41 \pm 0.064$ & $0.093 \pm 0.014$ \\
\hline C. bursa-pastoris & $0.21 \pm 0.032$ & $0.12 \pm 0.031$ \\
\hline D. nemorosa & $0.12 \pm 0.0023$ & $0.12 \pm 0.0046$ \\
\hline P. uralense & $13.17 \pm 0.22$ & $0.52 \pm 0.015$ \\
\hline E. densa & $13.45 \pm 0.38$ & $0.15 \pm 0.0073$ \\
\hline C. glaucum & $13.21 \pm 0.015$ & $0.082 \pm 0.0012$ \\
\hline H. monorchis & $0.0024 \pm 0.00$ & $0.011 \pm 0.0012$ \\
\hline P. depressa & $0.34 \pm 0.043$ & $0.27 \pm 0.012$ \\
\hline E. esula & $21.36 \pm 0.11$ & $0.091 \pm 0.0026$ \\
\hline E. palustre & $0.14 \pm 0.014$ & $0.18 \pm 0.0050$ \\
\hline E. arvense & $0.013 \pm 0.0011$ & $0.01 \pm 0.0010$ \\
\hline J. bufonius & $0.094 \pm 0.011$ & $0.015 \pm 0.0065$ \\
\hline
\end{tabular}

Seed mass and seed shape index values reflect the average value of each trait for plant species in both the warm- and coldseason pastures between grazing periods. Moreover, only mature seeds have the potential to germinate after passage through an animal's digestive tract, and therefore the size and composition of the dung seed bank differ between the warm and cold grazing seasons. However, we found that the dung seed bank properties did not differ significantly between the warm and cold seasons (Fig. 4a). The reason may be that plant seeds have persistent characteristics, i.e., seed retention in the plant canopy-the canopy seed bank (Ripa et al. 2020). This reproductive strategy prolongs the period during which seeds are dispersed and thus avoids the largescale death of offspring when unfavorable external factors persist. Although the warm season is the peak period for plant seed maturation on the QTP, the seeds of certain species remain on the mother plant and thus may be ingested by livestock during the cold season (Unpublished observations). In addition, light to moderate grazing (e.g., pasture in this study) would facilitate persistent seedheads (i.e., reproductive culms) in the pasture (Hu et al. 2018). This offers an explanation as to why 24 of the 43 plant species (56\%) we identified in the dung seed bank could germinate their seeds during both the warm and cold grazing seasons.

Of the 43 plant species that germinated from the yak dung collected during the two grazing seasons, only $12(28 \%)$ were annuals (Table 1), which indicated that the most significant contributions of the dung seed bank come from perennial species. Annuals rely only on seeds for reproduction and thus tend to produce a larger number of seeds (Uller and Olsson 2009) with 'r-selected' life-history characteristics, i.e., r-selection implies that plants produce large numbers of offspring to increase offspring survival (Mac-Arthur and Wilson 1967). Seeds that are produced in relative abundance, however, tend to be less tolerant to passage through the ruminant digestive tract (Lönnberg and Eriksson 2013), which contributes to the low seedling density found for annual plants in animal feces. Similar results were found in an analysis of the Tan sheep dung seed bank, which revealed that $80 \%$ of dung seedlings were perennials (Wang et al. 2019).

Effect of seed traits on the dung seed bank

Seed size and shape are significant plant adaptations for coping with environmental conditions (Wu et al. 2015), and these two characteristics also have a 

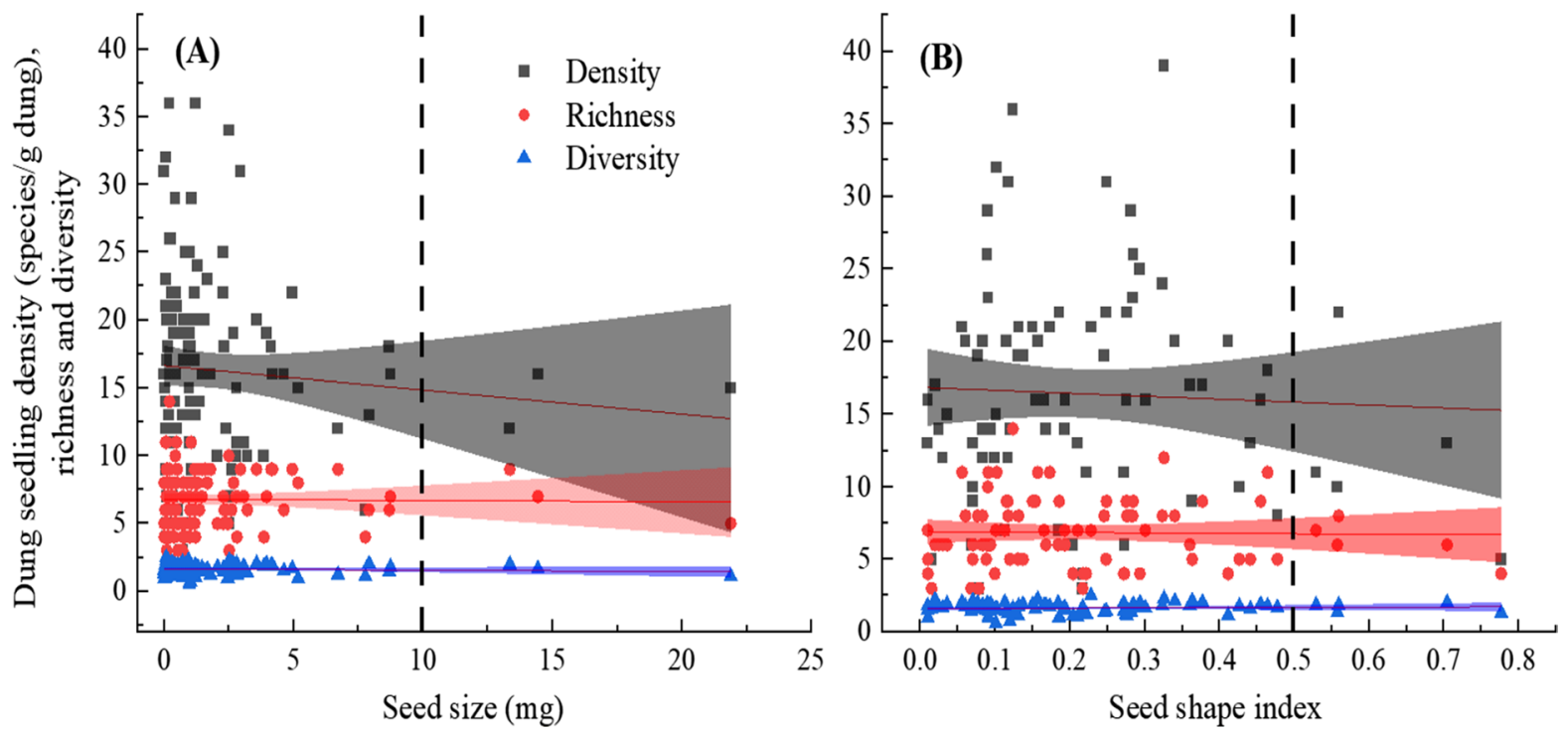

Fig. 5 Dung seedling density, species richness, and species diversity in relation to seed size (A) and seed shape index (B). The solid lines are significant regression lines. Shaded areas around the regression lines are $95 \%$ confidence intervals

significant impact on the ability of seeds to germinate after passing through the digestive tract of animals (Fig. 5; Fig. 8) (Wang et al. 2017). Of the 43 species that germinated from yak dung during the two grazing seasons, 33 species (77\%) had a seed size of $<10$ $\mathrm{mg}$ (small or medium seeds, according to the criteria of Thompson et al. (1993)) and 28 species (65\%) had a seed shape index of $<0.50$ (spherical seeds) (Peco et al. 2006) which correlated with greater germinability (Fig. 5). Larger seeds are more easily chewed. For example, Manzano et al. (2005) observed mastication of large-seeded species (e.g., Retama sphaerocarpa, $77 \mathrm{mg}$ ) based on broken seed fragments in sheep dung samples. Previous studies have indicated that small/medium seeds are better able to survive ingestion, escape molar grinding (Kuiters and Huiskes
2010), and survive gut passage (Pakeman et al. 2002). Small seed size and a spherical shape lead to a shorter retention time during digestion, reducing exposure to microbial attack in the rumen. These factors promote greater success of dispersal of viable seeds by endozoochory (Traveset 1998). Other researchers have suggested that viable small seeds are more likely than large seeds to be present in herbivore dungnot because small seeds are better adapted to survive gut passage but because of the negative relationship between seed size and seed production (Pakeman et al. 2002; Couvreur et al. 2005), i.e., small seeds are produced in greater numbers (Eriksson and Jakobsson 1998). However, Bruun and Poschlod (2006) and D'Hondt and Hoffmann (2015) observed no relationship between the potential for
Table 3 Mathematical relationships between dung seedling density, richness, and diversity and seed mass and seed shape index ( $\mathrm{n}$ $=43$ )

\begin{tabular}{lllll}
\hline Item & Equation & $\mathrm{R}^{2}$ & $\mathrm{~F}$ & $P$ value \\
\hline Seed mass $(\mathrm{mg})\left(\mathrm{X}_{1}\right)$ & & & & \\
Dung seedling density $\left(\mathrm{Y}_{1}\right)$ & $\mathrm{Y}_{1}=16.62-0.18 \mathrm{X}_{1}$ & 0.26 & 0.718 & 0.039 \\
Dung seedling richness $\left(\mathrm{Y}_{2}\right)$ & $\mathrm{Y}_{2}=6.80-0.01 \mathrm{X}_{1}$ & 0.23 & 0.027 & 0.047 \\
Dung seedling diversity $\left(\mathrm{Y}_{3}\right)$ & $\mathrm{Y}_{3}=1.65-0.01 \mathrm{X}_{1}$ & 0.75 & 0.831 & 0.011 \\
Shape index $\left(\mathrm{X}_{2}\right)$ & & & & \\
Dung seedling density $\left(\mathrm{Y}_{1}\right)$ & $\mathrm{Y}_{1}=16.86-2.04 \mathrm{X}_{2}$ & 0.19 & 0.154 & 0.044 \\
Dung seedling richness $\left(\mathrm{Y}_{2}\right)$ & $\mathrm{Y}_{2}=6.92-0.29 \mathrm{X}_{2}$ & 0.16 & 0.033 & 0.048 \\
Dung seedling diversity $\left(\mathrm{Y}_{3}\right)$ & $\mathrm{Y}_{3}=1.61-0.16 \mathrm{X}_{2}$ & 0.72 & 0.430 & 0.016 \\
\hline
\end{tabular}


Fig. 6 Yak forage preferences for the aboveground vegetation based on the calculation of Ivlev's index $(n=6)$. Data represent the weight of individual aboveground species during the warm grazing season. (+) Ivlev's index $>0$, indicating that yaks prefer to ingest those species; $(-)$ Ivlev's index $<0$, indicating a tendency to avoid those species. An Ivlev's index of 0 indicates that yaks consumed those species equally in both grazing seasons

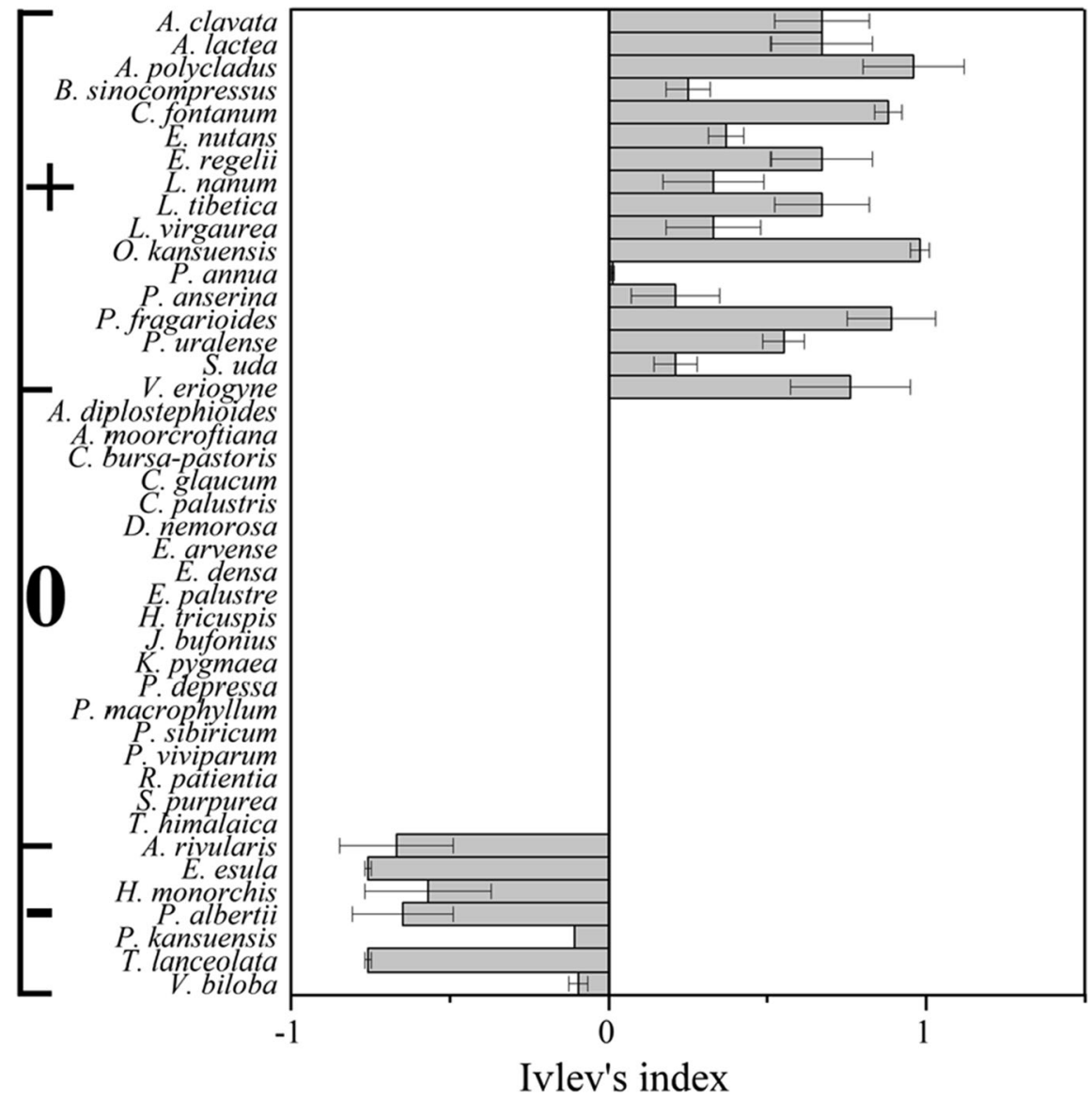

endozoochorous dispersal and seed characteristics such as size, shape, and thickness. Conflicting ideas about the relationship between seed characteristics and the potential for seed dispersal may be attributable, in part, to differences in plant or animal species (Wang et al. 2017; Wang et al. 2019).

\section{Forage preferences of grazing yaks}

Because the climate on the QTP varies greatly between seasons, herbivores face highly spatially heterogeneous food resource conditions. To meet their own nutritional needs and avoid the intake of poisonous plants, livestock must adopt effective foraging strategies (Newman et al. 1995). Forage preference is a survival strategy that evolved in herbivorous livestock to adapt to environmental conditions (Bagchi and Ritchie 2010). Of the 43 species that germinated from yak dung in our study, 36 species (83\%) had counterparts in aboveground vegetation, i.e.,
Ivlev's index $\geq 0$ (Fig. 6), implying that yaks prefer plants having a greater potential to survive the passage through their digestive tract. Other studies have shown that Kazakh sheep like to forage on poaceae and leguminosae species, and seeds of these plants are more likely to be dispersed via endozoochory (Wang et al. 2017).

Owing to the different nutritional components of forages in different phenological periods (Padilla and Curbelo 2004), the forage preferences of livestock differ between grazing seasons. The warm grazing season (from July to August) is the peak period of seed maturity and species richness of the aboveground vegetation, and nutritional value also peaks (Yao et al. 2019). Yaks show strong forage preference during this time, as 17 of 43 species (40\%) of the aboveground vegetation corresponded to dung seedling species having an Ivlev's index of $>0$ (Fig. 6), and therefore plant species that were preferred by yaks were more likely to appear in the 


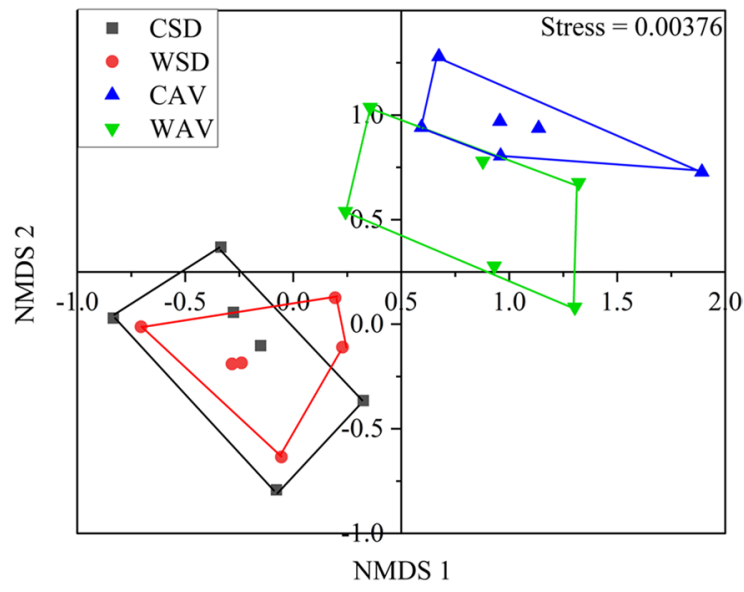

Fig. 7 Ordination diagram for each grazing season (six paddocks each) with respect to the density of the dung seedlings and aboveground vegetation based on nonmetric multidimensional scaling (NMDS) $(n=6)$. CSD and WSD refer to the density of cold-season dung seedlings and warm-season dung seedlings, respectively, and CAV and WAV refer to the density of the respective aboveground vegetation. Stress value $=$ 0.00376. Different colored quadrilaterals indicate different categories

dung. During the cold grazing season, because all forages are withered and the nutritional value is low, livestock can meet their own nutritional needs only by increasing their feed intake to obtain more dry matter content (because the dung dry matter weight was high at this time, Fig. 3). Thus, during the cold season, yak foraging options are minimal. Although some seeds are still retained on the canopy, the increase in feed intake results in an increase in seed density in dung (Table 1; Fig. 4). This further explains why the dung seed bank properties (density, richness and diversity) did not differ significantly between the two grazing seasons (Fig. 4).

Role of the dung seed bank in grassland management of the QTP

Spatial deposition of herbivore dung in grazing systems is important because it directly affects pasture growth and plant composition (Malo 2000). The spatial patterns of herbivore defecation result in interesting differences between and within plant communities. These differences are closely linked to the type of herbivore(s), its grazing behavior, and the distances over which it grazes (Malo 2000). Traditionally, grassland on the QTP has been used mainly for grazing, and livestock migrate between pastures. The majority of seeds passing through the digestive tract of yaks are retained for 12-96 h (Yu et al. 2012), which is long enough to result in seed dispersal over long distances. Indeed, endozoochorous seed dispersal distances are affected by grazing management. For example, free-grazing Kazakh sheep may wander 7-10 km per day (Wang et al. 2016), whereas the transhumant flocks of France and Spain, which move seasonally with their herders between fixed summer and winter pastures (Klein 1981), move 25-30 km per day, indeed facilitating seed dispersal over large distances (Manzano et al. 2005). In contrast, the yak is a semi-wild animal ( $\mathrm{Li}$ et al. 2017) that has relatively greater physical strength to travel large distances, and thus the range over which seeds are dispersed by yaks is greater than that covered by sheep. Unfortunately, no studies have reported the average daily distance traveled by yaks grazing on the QTP.

Seed dispersal by livestock is gaining recognition as a potential means for introducing desirable plant species into degraded or overgrazed grasslands (Oveisi et al. 2020). For this approach, the herder feeds the animals an appropriate pasture species with seeds that have sufficient dormancy and seed coat durability to survive passage through the gut and that retain viability in dung over long periods ( 500-1000 days, Yang et al. 2019). Upon the decomposition of dung, seeds can eventually flow into the soil seed bank and the corresponding plants can become established in the grassland. Livestock could be used to disperse native seeds with the aforementioned properties, particularly in remote and inaccessible areas (Gökbulak 2006). For example, Tan sheep could be used to disperse native seeds on the semiarid Loess Plateau (Wang et al. 2019). It should be noted, however, that endozoochory could potentially threaten functionally rich plant communities by assisting the spread of invasive weeds (Kuiters and Huiskes 2010). Given these various options, dispersal of desirable seed species can be achieved on the QTP through appropriate feed and targeted grazing of livestock (Lerner 2007; Bailey et al. 2019). Seed germination from animal dung is only the first step toward successful endozoochory, the second vital step being seedling establishment (Calviño-Cancela and Martín-Herrero 2009). Seeds of any plant species able 

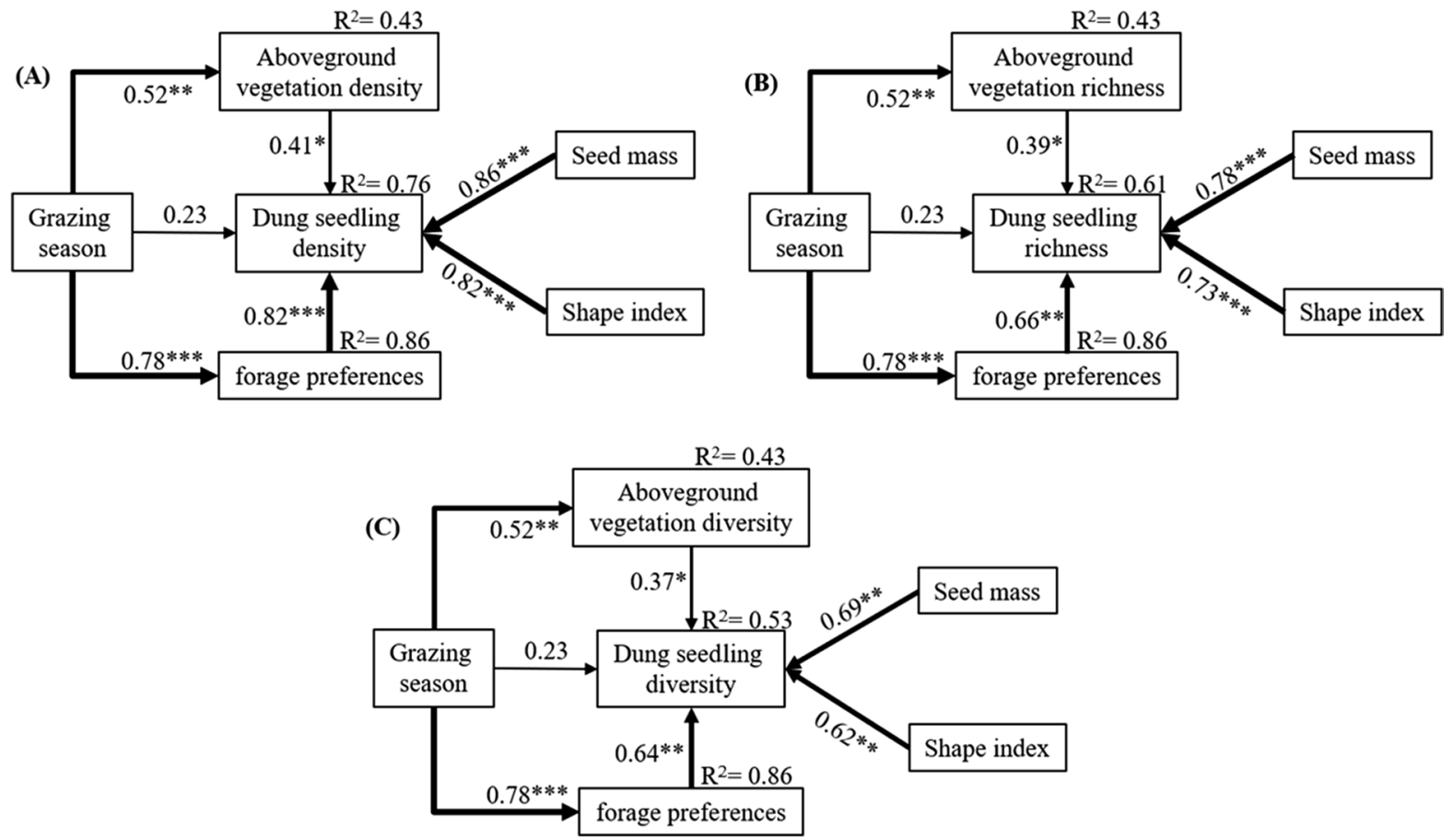

Fig. 8 Structural equation modeling of the relationships between the dung seedling bank and grazing season, yak forage preferences, and seed characteristics. Dung seedling and aboveground vegetation density data were used for the calculations. Numbers indicated above the arrows represent standardized path coefficients that reflect the effective strength of the

to retain viability after gut passage can be dispersed by animals, germinate, and subsequently establish a seedling (Barrow and Havstad 1992). Our study suggests that the foraging activities of yaks have the potential to contribute to the gathering of plant seeds under traditional rotational grazing on the QTP, as germinated seeds were detected in yak dung during both the warm and cold grazing seasons. Also, this mode of dispersal may help diversify plant communities on the QTP.

\section{Implications}

The results presented here only apply to the ability of seeds to germinate in dung. The survival, establishment, and development of seedlings are also very important, playing roles in the effectiveness of endozoochorous seed dispersal (Calviño-Cancela and Martín-Herrero 2009). Therefore, we recommend relationships. The proportion of variance explained is given as $\mathrm{R}^{2}$. ${ }^{*} P<0.05, * * P<0.01, * * * P<0.001$. (A-C) Results of model fitting. (A) Dung seedling density: $\chi^{2}=8.54$, $\mathrm{df}=5$, $P=0.18$. (B) Dung seedling richness: $\chi^{2}=7.62, \mathrm{df}=5, P=$ 0.16. (C) Dung seedling diversity: $\chi^{2}=5.54$, df $=5, P=0.12$

further investigation in the following areas: (i) studies of dung seedling growth and development to more clearly define the contributions of the dung seed bank to grassland vegetation renewal; (ii) observation of livestock grazing behaviors (e.g., spatial patterns and frequency of defecation, distances traveled, etc.) on the QTP grassland, followed by the determination of the directed dispersal of specific plant species through endozoochory, and finally examination of ongoing co-evolution between plants and animals, i.e., simultaneous evolution between interacting species (Maron et al. 2019; Valenta and Nevo 2020).

In addition, yak dung serves as a fuel for all heating and cooking on the QTP. About $40 \%$ of the total yak dung is deposited in the night pens, which is regularly collected and stored in manure heaps for drying for use as household fuel (Liu et al. 2017). This has induced soil nutrient and soil seed bank loss, and caused a serious impact on the natural restoration of grassland vegetation in the region. Therefore, how 
to crush yak dung and to return it to alpine meadow or artificial grassland is a new challenge for those engaged in the management of alpine meadow ecosystems on the QTP (Yu et al. 2012).

Acknowledgments The authors wish to thank Mr. Gericaidan (head of the Maqu Research Station) for field assistance.

Author contributions Shu-Lin Wang developed and implemented the research plan and wrote the manuscript. Fu-Jiang Hou contributed to the manuscript. All authors agreed to the final version of the manuscript and to its submission for publication.

Funding This research was supported by the Strategic Priority Research Program of the Chinese Academy of Sciences (XDA2010010203), the National Natural Science Foundation of China (31172249), and the Program for Innovative Research Team of Chinese Ministry of Education (IRT17R50).

Data availability statement Data supporting this article are available through Figshare: https://doi.org/10.6084/m9.figshare. 13685581 .

\section{Declarations}

Conflict of interest The authors declare that they have no conflict of interest.

Open Access This article is licensed under a Creative Commons Attribution 4.0 International License, which permits use, sharing, adaptation, distribution and reproduction in any medium or format, as long as you give appropriate credit to the original author(s) and the source, provide a link to the Creative Commons licence, and indicate if changes were made. The images or other third party material in this article are included in the article's Creative Commons licence, unless indicated otherwise in a credit line to the material. If material is not included in the article's Creative Commons licence and your intended use is not permitted by statutory regulation or exceeds the permitted use, you will need to obtain permission directly from the copyright holder. To view a copy of this licence, visit http://creativecommons.org/licenses/by/4.0/.

\section{References}

Arbuckle J (2010) IBM SPSS Amos 19 user's guide. Amos Development Corporation, Crawfordville, FL, pp 1-635

Bagchi S, Ritchie ME (2010) Introduced grazers can restrict potential soil carbon sequestration through impacts on plant community composition. Ecol Lett 13:959-968. https://doi.org/10.1111/j.1461-0248.2010.01486.x

Bailey DW, Mosley JC, Estell RE, Cibils AF, Horney M, Hendrickson JR, Walker JW, Launchbaugh KL, Burritt EA (2019) Synthesis Paper: Targeted Livestock Grazing:
Prescription for Healthy Rangelands. Rangeland Ecol Manag 72:865-877. https://doi.org/10.1016/j.rama.2019. 06.003

Barrow JR, Havstad KM (1992) Recovery and germination of gelatin-encapsulated seeds fed to cattle. J Arid Environ 22:395-399. https://doi.org/10.1016/0021-8502(92)90331-O

Bruun HH, Poschlod P (2006) Why are small seeds dispersed through animal guts: large numbers or seed size per se? Oikos 113:402-411. https://doi.org/10.1111/j.2006. 0030-1299.14114.x

Cai YJ, Wang XD, Tian LL, Zhao H, Lu XY, Yan Y (2014) The impact of excretal returns from yak and Tibetan sheep dung on nitrous oxide emissions in an alpine steppe on the Qinghai-Tibetan plateau. Soil Biol Biochem 76:90-99. https://doi.org/10.1016/j.soilbio.2014.05.008

Calviño-Cancela M, Martín-Herrero J (2009) Effectiveness of a varied assemblage of seed dispersers of a fleshyfruited plant. Ecology 90:3503-3515. https://doi.org/10. 1890/08-1629.1

Couvreur M, Cosyns E, Hermy M, Hoffmann M (2005) Complementarity of epi-and endozoochory of plant seeds by free ranging donkeys. Ecography 28:37-48. https://doi. org/10.1111/j.0906-7590.2005.04159.x

D'Hondt B, Hoffmann M (2015) A reassessment of the role of simple seed traits in mortality following herbivore ingestion. Plant Biology 13:118-124. https://doi.org/10. $1111 / \mathrm{j} .1438-8677.2010 .00335 . x$

Elisabeth B, Han O (2003) Impact of different-sized herbivores on recruitment opportunities for subordinate herbs in grasslands. J Veg Sci 14:465-474. https://doi.org/10. 1111/j.1654-1103.2003.tb02173.x

Eriksson O, Jakobsson A (1998) Abundance, distribution and life histories of grassland plants: a comparative study of 81 species. J Ecol 86:922-933. https://doi.org/10.2307/2648657

Grace JB (2006) Structural equation modeling and natural systems. Cambridge University Press, Cambridge, England, pp 324-348

Gökbulak F (2006) Recovery and germination of grass seeds ingested by cattle. Online J Biol Sci 6:23-27. https://doi. org/10.3844/ojbsci.2006.23.27

He MR, Xin CM, Baskin CC, Li JH, Zhao YP, An H, Sheng XJ, Zhao L, Zhao Y, Ma MJ (2020) Different response of transient and persistent seed bank of alpine wetland to grazing disturbance on the Tibetan Plateau. Plant Soil. https://doi.org/10.1007/s11104-020-04632-y

$\mathrm{Hu}$ A, Zhang J, Chen XJ, Chang SH, Hou FJ (2018) Winter grazing and rainfall synergistically affect soil seed bank in semiarid area. Rangeland Ecol Manag. https://doi. org/10.1016/j.rama.2018.07.012

Hurlbert SH (1984) Pseudoreplication and the design of ecological field experiments. Ecol Monogr 54:187-211. https://doi.org/10.2307/1942661

Iravani M, Schütz M, Edwards PJ, Risch AC, Scheidegger C, Wagner HH (2011) Seed dispersal in red deer (Cervus elaphus L.) dung and its potential importance for vegetation dynamics in subalpine grasslands. Basic Appl Ecol 12:505-515. https://doi.org/10.1016/j.baae.2011. 07.004

Jacobs J (1974) Quantitative measurement of food selection. Oecologia 14:413-417. https://doi.org/10.1007/BF00384581 
Janzen DH (1984) Dispersal of small seeds by big herbivores: foliage is the fruit. Am Nat 123:338-353. https://doi.org/ $10.2307 / 2461100$

Klein J (1981) La Mesta, 2nd edn. Spain, Alianza Editorial, Madrid

Kuiters AT, Huiskes HPJ (2010) Potential of endozoochorous seed dispersal by sheep in calcareous grasslands: correlations with seed traits. Appl Veg Sci 13:163-172. https:// doi.org/10.1111/j.1654-109X.2009.01058.x

Lerner D (2007) Targeted Grazing: A Natural Approach to Vegetation Management and Landscape Enhancement. Rangelands 29:69-69. https://doi.org/10.2111/1551-501X(2007) 29[69:BR]2.0.CO;2

Li ST, Liu JL, Liu AH, Li YQ, Wang SQ, Wang SF, Yin H, Luo JX, Guan GQ (2017) Molecular investigation of piroplasma infection in white yaks (Bos grunniens) in Gansu province, China. Acta tropica 171:220-225. https://doi. org/10.1016/j.actatropica.2017.04.009

Liu Y, Yan CY, Matthew C, Wood B, Hou FJ (2017) Key sources and seasonal dynamics of greenhouse gas fluxes from yak grazing systems on the Qinghai-Tibetan Plateau. Sci Rep 7:40857. https://doi.org/10.1038/srep40857

Liu SB, Zamanian K, Schleuss PM, Zarebanadkouki M, Kuzyakov Y (2018) Degradation of Tibetan grasslands: Consequences for carbon and nutrient cycles. Agr Ecosyst Environ 252:93-104. https://doi.org/10.1016/j.agee.2017. 10.011

Lönnberg K, Eriksson O (2013) Rules of the seed size game: contests between large-seeded and small-seeded species. Oikos 122:1080-1084. https://doi.org/10.1111/j.1600-0706.2012. 00249.X

Newman JA, Parsons AJ, Thornley JHM, Penning PD, Krebs JR (1995) Optimal diet selection by a generalist grazing herbivore. Funct Ecol 9:255-268. https://doi.org/10.2307/ 1937001

Mac-Arthur RH, Wilson EO (1967) The theory of island biogeography. Princeton University Press, Princeton, New Jersey, USA

Malo JE, Suárez F (1995) Establishment of pasture species on cattle dung: The role of endozoochorous seeds. J Veg Sci 6:169-174. https://doi.org/10.2307/3236211

Malo JE (2000) Hardseededness and the accuracy of seed bank estimates obtained through germination. Web Ecol 1:7075. https://doi.org/10.5194/we-1-70-2000

Manzano P, Manzano P, Malo JE, Peco B (2005) Sheep gut passage and survival of Mediterranean shrub seeds. Seed Sci Res 15:21-28. https://doi.org/10.1079/SSR2004192

Maron JL, Agrawal AA, Schemske DW (2019) Plant-herbivore coevolution and plant speciation. Ecology 100:1-11. https://doi.org/10.1002/ecy.2704

McNaughton SJ, Milchunas DG, Frank DA (1996) How can net primary productivity be measured in grazing ecosystems? Ecology 77:974-977. https://doi.org/10.2307/2265518

Myers JA, Vellend M, Gardescu S, Marks PL (2004) Seed dispersal by white-tailed deer: Implications for long-distance dispersal, invasion, and migration of plants in eastern north America. Oecologia 139:35-44. https://doi.org/10. 1007/s00442-003-1474-2

Nchanji AC, Plumptre AJ (2003) Seed germination and early seedling establishment of some elephant-dispersed species, Banyang-Mbo wildlife Sanctuary, Southwest
Cameroon. J Trop Ecol 19:229-237. https://doi.org/10. 2307/4091960

Oveisi M, Ojaghi A, Mashhadi HR, Heinz MS, Kamran RY, Behnaz PK, Elias S (2020) Potential for endozoochorous seed dispersal by sheep and goats: Risk of weed seed transport via animal faeces. Weed Res. https://doi.org/10. 1111/wre. 12461

Padilla C, Curbelo R (2004) Effect of the phenological stage on the quality and biomass production of wiregrass (Sporobolus indicus L.) RB. Cuban J Agr Sci 38:307-312

Pakeman RJ, Digneffe G, Small JL (2002) Ecological correlates of endozoochory by herbivores. Funct Ecol 16:296304. https://doi.org/10.2307/826582

Pain SJ, Corkran JR, Kenyon PR, Morris ST, Kemp PD (2014) The influence of season on lambs. Anim Prod Sci 55:1241-1249. https://doi.org/10.1071/AN14440

Peco B, Lopez-Merino L, Alvir M (2006) Survival and germination of Mediterranean grassland species after simulated sheep ingestion: ecological correlates with seed traits. Acta Oecologica 30:269-275. https://doi.org/10.1016/j. actao.2006.05.004

Pittarello M, Gorlier A, Lombardi G, Lonati M (2017) Plant species selection by sheep in semi-natural dry grasslands extensively grazed in the south-western Italian Alps. Rangeland J. https://doi.org/10.1071/RJ16068

Ripa RR, Franzese J, Premoli AC, Raffaele E (2020) Increased canopy seed-storage in post-fire pine invaders suggests rapid selection mediated by fire. Basic Appl Ecol 45:7685. https://doi.org/10.1016/j.baae.2020.04.002

Stroh PA, Mountford JO, Hughes FMR (2011) The potential for endozoochorous dispersal of temperate fen plant species by free-roaming horses. Appl Veg Sci. https://doi.org/ 10.1111/j.1654-109x.2011.01172.x

Sun Y, Angerer JP, Hou FJ (2015) Effects of grazing systems on herbage mass and liveweight gain of Tibetan sheep in Eastern Qinghai-Tibetan Plateau, China. Rangeland J 37:181-190. https://doi.org/10.1071/RJ14062

Sun Y, He XZ, Hou FJ, Wang ZF, Chang SH (2018) Grazing increases litter decomposition rate but decreases nitrogen release rate in an alpine meadow. Biogeoences 15:42334243. https://doi.org/10.5194/bg-15-4233-2018

Thompson K, Band SR, Hodgson JG (1993) Seed size and shape predict persistence in soil. Funct Ecol 7:236-241. https://doi.org/10.2307/2389893

Traveset A (1998) Effect of seed passage through vertebrate frugivores' guts on germination: A review. Perspect Plant Ecol 1:151-190. https://doi.org/10.1078/1433-8319-00057

Traveset A, Bermejo T, Willson M (2001) Effect of manure composition on seedling emergence and growth of two common shrub species of Southeast Alaska. Plant Ecol 155:29-34. https://doi.org/10.1023/A:1013282313035

Uller T, Olsson M (2009) Offspring size-number trade-off in a lizard with small clutch sizes: tests of invariants and potential implications. Evol Ecol 23:363-372. https://doi. org/10.1007/s10682-007-9231-3

Valenta K, Nevo O (2020) The dispersal syndrome hypothesis: how animals shaped fruit traits, and how they did not. Funct Ecol 34:1158-1169. https://doi.org/10.1111/1365-2435.13564

Wang XT, Zhang DG, Shi SL (2012) Rangeland nomadic culture of the Yugur (II) - production culture of the Yugur. 
Grassland Turf 32:76-78. https://doi.org/10.13817/j.cnki. суyср.2012.01.003

Wang CJ, Wang WQ, Lu WH, Wen CL, Yin XJ, Zhao QZ (2016) Feed intake distribution model for herd based on grazing spatio-temporal trajectory data. Trans Chinese Soc Agric Eng 32:125-130. https://doi.org/10.11975/j. issn.1002-6819.2016.13.018

Wang SL, Lu WH, Waly N, Ma CH, Zhang QB, Wang CJ (2017) Recovery and germination of seeds after passage through the gut of Kazakh sheep on the north slope of the Tianshan Mountains. Seed Sci Res 27:43-49. https://doi. org/10.1017/S0960258517000022

Wang SL, Lu WH, Chen YS, Jing PC (2018) Effect of sheep digestive tract on the recovery and germination of seeds of fifteen leguminous plants in the northern Xinjiang region, China. Chinese J Plant Ecol 42:185-194. https://doi.org/ 10.17521/cjpe.2017.0118

Wang SL, Hu A, Zhang J, Hou FJ (2019) Effects of grazing season and stocking rate on seed bank in sheep dung on the semiarid Loess Plateau. Rangeland J 41:405-413. https://doi.org/10.1071/RJ19036

Wang YX, Sun Y, Chang SH, Wang ZF, Hou FJ (2020) Restoration practices affect alpine meadow ecosystem coupling and functions. Rangel Ecol Manag 73:441-451. https:// doi.org/10.1016/j.rama.2020.01.004

Woldu Z, Saleem MAM (2000) Grazing induced biodiversity in the highland ecozone of East Africa. Agr Ecosyst Environ 79:43-52. https://doi.org/10.1016/S0167-8809(99) 00141-3

Wu GL, Shang ZH, Zhu YJ, Ding LM, Wang D (2015) Species-abundance - seed-size patterns within a plant community affected by grazing disturbance. Ecol Appl 25:848-855. https://doi.org/10.1890/14-0135.1
Yao XX, Wu JP, Gong XY, Lang X, Wang CL, Song SZ, Ahmad AA (2019) Effects of long term fencing on biomass, coverage, density, biodiversity and nutritional values of vegetation community in an alpine meadow of the Qinghai-Tibet Plateau. Ecol Eng 130:80-93. https://doi. org/10.1016/j.ecoleng.2019.01.016

Yang CT, Zhang Y, Hou FJ, Millner JP, Chang SH (2019) Grazing activity increases decomposition of yak dung and litter in an alpine meadow on the Qinghai-Tibet plateau. Plant Soil 444:1-12. https://doi.org/10.1007/ s11104-019-04272-x

Yu XJ, Xu CL, Wang F, Shang ZH, Long RJ (2012) Recovery and germinability of seeds ingested by yaks and Tibetan sheep could have important effects on the population dynamics of alpine meadow plants on the Qinghai-Tibetan Plateau. Rangeland J 34:249-255. https://doi.org/10.1071/ RJ12010

Yu XJ, Xu CL, Wang F, Shang ZH, Long RJ (2013a) Levels of germinable seed in topsoil and yak dung on an alpine meadow on the Northeast Qinghai-Tibetan Plateau. J Integr Agr 12:2243-2249. https://doi.org/10.1016/S20953119(13)60652-8

Yu XJ, Xu CL, Muhammad I, Long RJ (2013b) Effects of yak dung patch dropped in cold season on soil and pasture on the Qinghai-Tibetan Plateau. Acta Ecologica Sinica 33:241-244. https://doi.org/10.1016/j.chnaes.2013.07.001

Zhouguadongzhu, (2019) A study on the vicissitude of livelihood of Maqu nomadic society. Qinghai Nationalities University, Master theses, Xining

Publisher's Note Springer Nature remains neutral with regard to jurisdictional claims in published maps and institutional affiliations. 